C00-1140-205

1972, October 31

\title{
HIGH TEMPERATURE CHEMISTRY
}

Progress Report

Paul W. Gilles

Principal Investigator

\author{
Department of Chemistry \\ University of Kansas \\ Lawrence, Kansas 66044
}

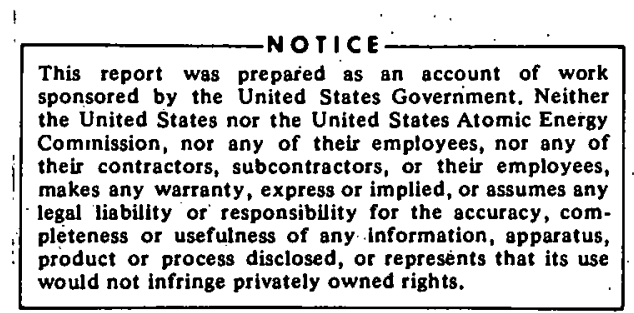

1971,.. November I to 1972, October 31

Prepared for the U. S. Atomic Energy Commission under Contract No. AT(1i-1)-1140, Modification. No. 8-2. 


\section{DISCLAIMER}

This report was prepared as an account of work sponsored by an agency of the United States Government. Neither the United States Government nor any agency Thereof, nor any of their employees, makes any warranty, express or implied, or assumes any legal liability or responsibility for the accuracy, completeness, or usefulness of any information, apparatus, product, or process disclosed, or represents that its use would not infringe privately owned rights. Reference herein to any specific commercial product, process, or service by trade name, trademark, manufacturer, or otherwise does not necessarily constitute or imply its endorsement, recommendation, or favoring by the United States Government or any agency thereof. The views and opinions of authors expressed herein do not necessarily state or reflect those of the United States Government or any agency thereof. 


\section{DISCLAIMER}

Portions of this document may be illegible in electronic image products. Images are produced from the best available original document. 
C00-1140-205

1972 , October 31

\section{INTRODUCTION}

This Progress Report is divided into six parts which describe Education, Publications and Papers at Meetings, Research Progress Highlights, Space and Facilities, Level of Activity, and Miscellaneous.

\section{EDUCATION}

To Los Alamos goes Peterson; to International Nickel goes Conard; to du Pont goes Chen. Thus continues the ongoing entrance into mature scientific productivity by graduates of the program. The education of graduate students, undergraduate students, and postdoctoral research associates in high temperature chemistry and associated fields of interest to the Atomic Energy Commission is one of the continuing and most important purposes of this contract.

Dean E. Peterson will complete his Ph.D. degree in November and will immediately assume a staff position at Los Alamos, there to work with $\mathrm{Dr}$. R. N. R. Mulford. He will investigate the thermodynamics of multi-component oxide systems at high temperature, an activity for which his educational program admirably has prepared him. Dr. Bruce R. Conard who has been a postdoctoral research associate has chosen the industry route with International Nickel and will investigate vapor phase transport processes by means of mass spectrometry and conventional studies. He has received education and training in both of these areas so that he is in a position to make immediate contributions. For example, in a recent four-day visit to International Nickel he brought to the attention of the laboratory director the availability of the commercial mass spectrometer most suitable for his work and arranged for its purchase. Dr. Horng-yih Chen, who received his Ph.D. degree in 1968 from the University, has moved from the Ames Laboratory at Iowa State to the Solid State Division in the Central Research Department at du Pont where he will prepare and characterize high temperature materials.

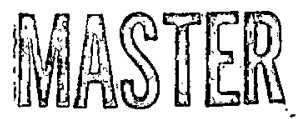

Advancements in positions have come to four previous students and postdoctoral research associates. Prof. John L. Margrave, a former graduate student, has become Dean of Advanced Studies and Research at Rice University. Professor Phillip G. Wahlbeck, postdoctoral research associate 1958-1960, has been appointed 
COO-1140-205

1972 , October 31

Page 2

chairman of the Chemistry Department at Wichita State University, Wichita, Kansas. The proximity of Wahlbeck at Wichita State ought to make possible joint activities. Prof. Harry A. Eick, postdoctoral research associate in 1957-1958, has been acting director of the Computation Center at Michigan State. Dr. Sven Westman, postdoctoral research associate 1950-1961, has earned the highly-valued Swedish Doctor's Degree in Stockholm.

Tables I, II, and III summarize the past and present educational products of the program. Table I gives in chronological order of graduation, the names, the dates, and the locations of the scientists who have completed education in high temperature chemistry at the University of Kansas. In Table II, the same information is given, but the names are arranged according to the type of installation. Table III gives the names of the people currently in high temperature research. The count now stands at nineteen Ph.D.'s, sixteen postdoctoral research associates, and six masters. These scientists and their accomplishments attest to the educational value of the program.

The international flavor of the program merits some notice. Of the nineteen Ph.D. students three were from outside the U.S. and all are from Taiwan. Two now have permanent positions in this country, and the third is in a postdoctoral position in the U.S. Of the ten foreign-born postdoctoral research associates seven are now in their home countries; two are in permanent positions and one is in a postdoctoral position in the U.S. Of the Ph.D. students of U.S. origin, four have had European experience and one experience in India. of the native postdoctoral research associates two have had subsequent European experience.

About twenty-six of the scientists more or less, some 63 percent, are currently engaged in high temperature research. Thirteen are in universities, one in a college, six in AEC laboratories, six in other research establishments, ten in industry, three in postdoctoral study, and two uncertain.

Capable, educated people are the products of an educational program. At least fourteen of the people listed in Tables I and II have substantial international reputations because of their research. Others are known on their 
COO-1140-205

1972 , October 31

Page 3

respective national levels. Attention is drawn to the accomplishments of the people in the AEC laboratories, Ackermann, Leitnaker, Smith, Hobrock, Unruh and Jackson, and, in addition Franzen, who is listed at Iowa State University and also in the Ames Laboratory. In the AEC Iaboratories at least five people, Leitnaker, Franzen, Smith, Unruh, and Hobrock have planning and supervisory responsibilities. One of the purposes of the contract is to aid in the training of scientists skilled in branches of chemistry of interest to the Atomic Energy Commission, and the presence of these men in the AEC program clearly demonstrates the accomplishments achieved. When Peterson assumes his new position the major AEC research sites having graduates from the program will be Hanford, Livermore, Los Alamos, Ames, Argonne, Mound, Oak Ridge, and Savannah River, thus leaving only Brookhaven and Berkeley without.

Their work in the AEC laboratories has been on the high temperature properties of the uranium-oxygen system, the rare earth-oxygen systems, the curium-oxygen system, the uranium-sulfur system, the uranium-carbon-nitrogen system, the rare earth-carbon systems, the metal-rich sulfides, mass spectrometry, and radiation monitoring.

During the current year one new postdoctoral research associate, C. Larry Sullivan, and one new graduate student, Gary H. Rinehart, have joined the program.

The Gordon Research Conference in High Temperature Chemistry vas held at Proctor Academy, Andover, New Hampshire, 1972, August 7-11. Former and present students and postdoctoral research associates participated. Professor K. Douglas Carlson was Chairman of this conference; Professor E. David Cater and Dr. Frank T. Greene each arranged a day's session. Professor H. F. Franzen was on the scheduled program; Edwards, Peterson, Cater, Behrens and Conard gave brief reports. Franzen and Gilles served on the Nomination Committee; Wahlbech, Cater and Greene served on the Recommendations Committee. In all, ten students and six postdoctoral research associates attended.

In order to enrich the graduate and postdoctoral educational opportunities visitors are brought to the University. Table IV lists 22 seminar talks of more or less interest to high temperature chemists. Of these, Professors 
COO-1140-205

1972, October 31

Page 4

Stafford, Schoonmaker, Grimley, Wahlbeck, Spear, and Dr. Lin came especially to the High Temperature group. Other scientists in the high temperature field who visited but who did not give talks, were Mr. James R. McCreery of Argonne National Laboratory; Dr. John B. Wachtman, Jr., Director, Inorganic Materials Division, Institute of Materials Research, National Bureau of Standards; Dr. Thomas A. Milne, Midwest Research Institute, Kansas City, Missouri; and Professor Hugo F. Franzen, Department of Chemistry and Ames Laboratory, Iowa State University, Ames, Iora.

\section{PUBLICATIONS AND PAPERS AT MEETINGS}

The permanent, public record is contained in two published articles and one article submitted for publication as detailed in Table V. That the publication rate is low is recognized, but the prospects for immediate improvement are excellent. In nearly completed form are a paper on the titanium-oxygen system, a paper on the vanadium-tungsten-oxygen system, and a paper on the hydrogen-boron-silicon system. Less far advanced are two papers on the rare earth-sulfur system.

Ten talks based on scientific work are listed in Table VI. Talk number T-163 was based on developments occurring under an NSF grant, and talk number T-164 presented at a symposium in Europe covered results obtained under an AROD grant. Travel to the conference was made without the use of AEC funds.

\section{RESEARCH HIGHLIGHTS}

The completed work is described by the publications. Manuscripts submitted for publication and reprints have been submitted to the contracting officer in the usual fashion; the contents of those appearing in journals will not be repeated here. The work will be described in the following categories: 1) vaporization behavior of refractory systems;2) high molecular weight inorganic gaseous substances; 3) kinetics of high temperature vaporization reactions.

(1) Vaporization Behavior of Refractory Systems. During the current year Dr. Bruce R. Conard has obtained significant results in the investigation of 
C00-1140-205

1972, October 31

Page 5

the vaporization and thermodynamic properties of the titanium oxides.

Previous work has indicated that the composition of the congruently vaporizing solution in the binary titanium-oxygen system lies in the $\mathrm{Ti}_{3} \mathrm{O}_{5}$ solid solution range and that $\mathrm{TiO}(\mathrm{g})$ and $\mathrm{TiO}_{2}(\mathrm{~g})$ are the important gaseous products of the vaporization reaction. Recent evaluations of some of the earlier results have shown that at $1900-2000^{\circ} \mathrm{K}$ the composition of congruently vaporizing $\mathrm{Ti}_{3} \mathrm{O}_{5}$ is $\mathrm{O} / \mathrm{Ti}=1.70 \pm 0.02$ and the range of homogeneity in the $\mathrm{Ti}_{3} \mathrm{O}_{5}$ region is $0.04 \pm 0.01$. To put it differently, the $\mathrm{Ti}_{3} \mathrm{O}_{5}$ phase extends from about $0 / \mathrm{Ti}=1.68$ to 1.72 . This result is one of the very few measurements . on the extent of nonstoichiometry at temperature, the other notable ones in oxide systems being $\mathrm{Fe}_{1-\mathrm{x}} \mathrm{O}$ and $\mathrm{UO}_{2+\mathrm{x}}$.

In all mass spectrometric studies the extent of fragmentation of parent ions in the ionization region is a source of uncertainty. Similarly, crosssections of ionization are another source of uncertainty. Previous measurements have indicated that the extent of fragmentation of $\mathrm{TiO}^{+}$to $\mathrm{Ti}^{+}$was about 10\%. This result was based on the relative intensities of $\mathrm{Ti}^{+}$and $\mathrm{TiO}^{+}$ over samples in which the chemical potential of oxygen was sufficiently high that gaseous titanium atoms were insignificant. But the degree of fragmentation of $\mathrm{TiO}_{2}{ }^{+}$, remained unknown, and a lack of this knowledge imposed a serious limitation on attempts to use the $\mathrm{TiO}_{2}^{+} / \mathrm{TiO}^{+}$ratio for measurements of the chemical potential of oxygen in complex oxide systems. Dr. Conard's calculations of Hampson's results from the $\mathrm{Ti}_{3} \mathrm{O}_{5}-\mathrm{Ti}_{4} \mathrm{O}_{7}$ region showed that the extent of fragmentation of $\mathrm{TiO}_{2}{ }^{+}$to give $\mathrm{TiO}^{+}$was less than $22 \%$. In order to get a reliable estimate of this figure, new experiments have been performed.

These experiments were performed in a specially designed tetragonal (not tetrahedral) crucible containing four chambers. One contained a platinum liner, two contained iridium liners, and the fourth contained no Iiner and hence acted as a tungsten crucible.

Samples of $\mathrm{TiO}_{2}(\mathrm{~s})$ were used because they have an even greater oxygen potential which is sufficiently high that TiO $(\mathrm{g})$ is not an irportant vapor constituent. Thus, any $\mathrm{TiO}^{+}$observed is a fragment of $\mathrm{TiO}_{2}^{+}$. The measurements 
COO-1140-205

1972, October 31

Page 6

were completed during the past week, and a preliminary analysis reveals that the extent of fragmentation of $\mathrm{TiO}_{2}{ }^{+}$at $70 \mathrm{eV}$ is less than $5 \%$, and probably nearly zero,

The present state of the high temperature vaporization and thermodynamics of the titanium oxides stands as follows. The congruently vaporizing solution lies in the $\mathrm{Ti}_{3} \mathrm{O}_{5}$ phase range; its composition is $\mathrm{TiO}_{1.70} \pm 0.02$; its range of homogeneity at temperature is $0.04 \pm 0.01$; its gaseous products are TiO ( $\mathrm{g}$ ) and $\mathrm{TiO}_{2}(\mathrm{~g})$; their fragmentation amounts to about $10 \%$ to $\mathrm{Ti}^{+}$and less than $5 \%$ to $\mathrm{TiO}^{+}$, respectively; their dissociation energies are those given by Hampson and Gilles as 157 and $312 \mathrm{kcal} / \mathrm{mole}$.

The recently published value $144:$ cal/mole for the dissociation energy of TiO from Rome was based on mass spectrometric investigations of lunar samples and is much lower than the value 157 obtained in this leboratory; it is, in our firm belief, incorrect. It is so low that for it to be correct, many thermodynamic values or measurements for other compounds must be altered -- an unlikely situation. The suspected source of their error is their reliance on a measurement of an ion ratio supposed to be $\mathrm{O}_{2}^{+} / \mathrm{O}^{+}$, and this suggestion has been transmitted to them.

During the course of this work the data acquisition and equipment control system was used extensively, and it enabled much better data to be taken than was possible previously.

During the past year our ideas on the interpretation of mass spectrometric measurements have been clarified. In mass spectrometric studies of refractory materials the intensities of various ions can be measured, and the intensities of those ions, when corrected for fragmentation, can be indicative of the pressures of the gaseous substances in the crucible containing the vaporizing samples. The pressures of gaseous substances are determined by thes crn tifemochomical properties and by the chemical potentials of the comporents in the sanple and the tomperature. The intensities of the ions are influenced $\mathrm{ry}$ monj factors, kut. are proportional to the quotients of the pressures and the temperature. 
c00-1140-205

1972, October 31

Page 7

Thus, in a binary oxide system the intensity ratio $\mathrm{MO}_{2}^{+} / \mathrm{MO}^{+}$indicates the ratio of pressures $\mathrm{MO}_{2}(\mathrm{~g}) / \mathrm{MO}(\mathrm{g})$. After a sample has been held at constant temperature for a sufficiently long period of time so that the intensity ratio $\mathrm{MO}_{2}+/ \mathrm{MO}^{+}$has become constant, a measurement of the ratio indicates the oxygen potential of the system. Such a system can be a congruently vaporizing solution or can consist of two solid phases in equilibrium with each other.

Consider the case of a congruently vaporizing solution (CVS). If after a constant ion intensity ratio has been achieved, the temperature is changed, the intensity ratio will probably change. Two different points of view or attitudes can be taken regarding this change. The first and simpler attitude is that the observed intensity ratio indicates the oxygen-potential in the new CVS which has a different composition from the original one. The second attitude is that the intensity ratio indicates the proportions in which the two species are leaving the system in its attempt to achieve a new composition. These two attitudes, characterized as "at equilibrium" and "on the fly", give directly opposite results regarding the temperature coefficient of the composition of the CVS.

Take for example a binary oxide system in which the composition of the CVS is more oxygen-rich at a higher temperature than at a lower temperature. Suppose that the cVS has been reached at the lower temperature. As the temperature is raised, the system must lose relatively more metal than oxygen in order to reach the new congruently vaporizing solution. Thus, initially the intensity ratio $\mathrm{MO}_{2}{ }^{+} / \mathrm{MO}^{+}$will be smaller than before the temperature change in order that more metal vaporize. As the vaporization proceeds at the new and higher temperature, the $\mathrm{MO}_{2}{ }^{+} / \mathrm{MO}^{+}$ratio will increase and ultimately will approach an equilibrium value larger than that measured before the temperature change. Put differently, before equilibrium is reached at the higher temperature the $\mathrm{MO}_{2}^{+} / \mathrm{MO}^{+}$ratio can be either smaller or larger than before the temperature change. Hence, the moment at which a measurement is made is a crucial datum in the interpretation of the measurements. The necessity of watching the change in the ratio as vaporization proceeds in order to ascertain whether equilibrium has been reached 
c00-1140-205

1972 , October 31

Page 8

is thus quite clear. In those cases in which the composition of the CVS changes with temperature, considerable patience must be exercised. These seemingly obvious considerations are not always realized and are rarely discussed.

The dissociation energies of gaseous sulfides are smaller than corresponding oxides, but yet large enough so that the molecules are important constituents in the gaseous phase arising from vaporizing material. In order to measure dissociation energies, absolute vapor pressure studies in this laboratory have been made recently on the substances GaS, CeS, and TiS; work in other laboratories has been performed on US, SrS, EUS, PrS, YS, and LaS. In addition, several isomolecular exchange reactions have been studied both here and elsewhere. The discrepancies are several, and the trends in the dissociation energies can be seen only generally.

In order to pinpoint areas in which further work is needed Dr. Robert G. Behrens has summarized the available information on the heat capacities, entropies, and enthalpy increments for the rare-earth sulfides. One of the largest uncertanties arises from lack of knowledge of the electronic states. He has estimated in a consistent way the missing values and has calculated a consistent set of thermodynamic properties, particularly the free energy function, for all the rare-earth monosulfides as well as TiS, GeS, SiS and US. Moreover, he has reviewed the previous work on the dissociation energies of these substances. These studies have shown that the single most important study is to measure mass spectrometrically the equilibrium constant for the reaction,

$$
\mathrm{GdS}+\mathrm{Ti}=\mathrm{Gd}+\mathrm{TiS},
$$

f'solute vaporization studies have been performed on both solid materials in substantielly the same apparatus, and both gaseous molecules have been studied in the sane mass spectrometer. This study will link for one of the few times two absolute vapor pressure measurements. Because the Nuclide Mass Spectrometer was being used foi studies of titanium oxides, Dr. Behrens did not have an opportunity to pursus the vaporization studies either of the rare-earth borides or the rare-earth suffides. He is now, however, ready to go with the investigation of both of these studies. He will begin with the sulfides. The materials and crucible have been prepared, and the experiment should be under way in the 1972 , October 31 
COO-1140-205

1972 , October 31

Page 9

third week of November.

(2) High Molecular Weight Inorganic Gaseous Substances. A paper on a mass spectrometric investigation of the vanadium-tungsten-oxygen system has been prepared and is nearly ready for submission for publication. In this work the vaporization of mixtures of $\mathrm{V}_{2} \mathrm{O}_{5}$ and $\mathrm{WO}_{3}$, followed by electron impact, yeilded a plethora of ionic species consisting of forty-one binary, twenty-five ternary, and fifteen metastable decomposition reactions. The largest ternary species observed was $\mathrm{VW}_{4} \mathrm{O}_{14}^{+}$at 1,011 amu. From relative ion intensities, appearance potential measurements, temperature coefficient measurements, and the assignment of metastable decomposition reactions, the parent and fragment ions have been identified and partially characterized.

The gaseous species $\mathrm{O}_{2}, \mathrm{VO}_{2}, \mathrm{~V}_{4} \mathrm{O}_{10}, \mathrm{~V}_{4} \mathrm{WO}_{11}, \mathrm{~V}_{3} \mathrm{~W}_{2} \mathrm{O}_{13}, \mathrm{~V}_{2} \mathrm{~W}_{3} \mathrm{O}_{14}, \mathrm{VW}_{4} \mathrm{O}_{14}, \mathrm{~W}_{6} \mathrm{O}_{18}$, $\mathrm{W}_{5} \mathrm{O}_{15}, \mathrm{~W}_{4} \mathrm{O}_{12}$ and $\mathrm{W}_{3} \mathrm{O}_{9}$ are present. In addition, while a portion of the $\mathrm{W}_{2} \mathrm{O}_{6}{ }^{+}$, $\mathrm{W}_{3} \mathrm{O}^{+}, \mathrm{W}_{4} \mathrm{O}_{11}{ }^{+}, \mathrm{W}_{5} \mathrm{O}_{14^{+}}, \mathrm{WW}_{2} \mathrm{O}_{8}^{+}, \mathrm{V}_{2} \mathrm{~W}_{2} \mathrm{O}_{10^{+}}, \mathrm{V}_{3} \mathrm{WO}_{10^{+}}$, and $\mathrm{VW}_{3} \mathrm{O}_{11}^{+}$ion signals could have resulted from dissociative ionization, the corresponding gaseous molecules may also exist. During the initial stages of the vaporization, $\mathrm{V}_{6} \mathrm{O}_{15}, \mathrm{~V}_{4} \mathrm{O}_{8}$, and $\mathrm{V}_{4} \mathrm{~W}_{2} \mathrm{O}_{16}$ gases probably also exist.

The studies indicate the existence of many previously unknown high molecularwoight ternary ions and many metastable decomposition reactions. High molecularweight vanadium-rich species are present during the initial stages of vaporization of mixtures of $\mathrm{V}_{2} \mathrm{O}_{5}$ and $\mathrm{WO}_{3}$ but they quickly disappear as the composition moves into the two-phase $\mathrm{VO}_{2} \cdot \mathrm{rWO}_{3}$ region. The partial pressures of all remaining species except $\mathrm{V}_{4} \mathrm{O}_{10^{+}}, \mathrm{V}_{4} \mathrm{WO}_{11}{ }^{+}, \mathrm{O}_{2}^{+}$, and $\mathrm{O}^{+}$increase with increasing temperature until the composition of the residue reaches the $\mathrm{VO}_{2}+\mathrm{WO}_{2}$ solid solution region. At this point, corresponding to loss of $\mathrm{WO}_{3}$ from the sample, there is a reduction in all Ion intensities.

(3) Kinetics of High Temperature Vaporization Reactions. Mr. Dean E. Peterson has completed his Ph.D. thesis, and it is now in the proofreading stage. His dissertation concerns a thermodynamic and kinetic study of the sublimation of cuprous chloride and is divided into two major parts. The first part relates 
coo-1140-205

1972 , October 31

Page 10

to research performed with the vacuum balance-torsion apparatus. Total vapor pressures, vapor compositions, and heats and entropies of sublimation determined for the sublimation of zinc metal and cuprous chloride are presented. The second part relates to the mass spectrometric measurements conducted on the sublimation of cuprous chloride. The partial pressures and heat and entropy of sublimation measured for each vapor species are given in this part. The same mechanism for the sublimation reaction of $\mathrm{CuCl}$ is proposed in each part, and a theoretical interpretation of the kinetics based on absolute reaction rate theory is given at the end of the second part.

Part I. Simultaneous Knudsen weight loss and Knudsen torsion pressure measurements were completed on the sublimation of zinc metal in order to verify satisfactory operation of the vacuum balance-torsion apparatus. The second law heat and entropy of sublimation determined at $560^{\circ} \mathrm{K}$ from the weight loss data for zinc were $30.4(0.4) \mathrm{kcal} / \mathrm{mole}$ and $27.1(0.8)$ eu. respectively.

Knudsen weight loss and Knudsen torsion pressures were simultaneously measured for the equilibrium sublimation of cuprous chloride. The composition calculated for the equilibrium vapor at $584^{\circ} \mathrm{K}$ was $56(4)$ mole \% trimer and 44(4) mole \% tetramer. The second law heat and entropy of sublimation determined at $584^{\circ} \mathrm{K}$ from the torsion measurements were $34.4(0.4) \mathrm{kcal} / \mathrm{mole}$ and $34.0(0.7) \mathrm{eu}$. respectively.

Simultaneous measurements of the Langmuir weight loss and Langmuir torsion pressures over a freely subliming $\mathrm{CuCl}$ single crystal face (111). were performed in order to determine the kinetic sublimation properties. The nonequilibrium vapor composition calculated at an average temperature of $523^{\circ} \mathrm{K}$ was $85(6)$ mole $\%$ trimer and 15(6) mole \% tetramer. The activation heat and entropy of sublimation determined at an average temperature of $523^{\circ} \mathrm{K}$ from the torsion pressures were $33.9(0.2) \mathrm{kcal} / \mathrm{mole}$ and $30.8(0.4)$ eu. respectively. An opposed Knudsen and Langmuir weight loss and differential torque experiment was also performed, and it verified the relative magnitude of the Knudsen and Langmuir pressures.

Part II. The composition of the $\mathrm{CuCl}$ vapor was measured in equilibrium and nonequilibrium sublimation experiments by employing a Nuclide mass spectrometer connected to a data acquisition and equipment control system. The relative 1972 , October 31 
c00-1140-205

1972, October 31

Page 11

intensity, appearance potential, and temperature coefficient of intensity were measured for each of the shutterable $\mathrm{CuCl}$ ion species. Fragmentation phenomena occurring upon electron bombardment of the neutral vapor species were investigated in order to reveal the precursor of each fragment. Estimates of the bond and dissociation energies of the trimer and tetramer molecules were obtained from a comparison of the appearance potentials of the parent and fragment ions observed in the equilibrium mass spectrometer experiments. The standard heats and entropies of sublimation determined for the trimer and tetramer at an average temperature of $526^{\circ} \mathrm{K}$ and for the pentamer at $566^{\circ} \mathrm{K}$ were as follows: $\mathrm{Cu}_{3} \mathrm{Cl}_{3}\left(\Delta \mathrm{H}^{\circ}=33.1(0.3) \mathrm{kcal} / \mathrm{mole}, \Delta \mathrm{S}^{\circ}=30.8(0.5)\right.$ eu. $) ; \mathrm{Cu}_{4} \mathrm{Cl}_{4}$ $\left(\Delta \mathrm{H}^{\circ}=35.7(0.2) \mathrm{kcal} / \mathrm{mole}, \Delta \mathrm{S}^{\circ}=34.4(0.5) \mathrm{eu}.\right)$; and $\mathrm{Cu}_{5} \mathrm{Cl}_{5}\left(\Delta \mathrm{H}^{\circ}=\right.$ 43.9(0.7) $\left.\mathrm{kcal} / \mathrm{mole}, \Delta \mathrm{S}^{\circ}=36.9(1.3) \mathrm{eu}.\right)$.

The nonequitibriun sublimation of vapor. species arising from the (111) face of a $\mathrm{CuCl}$ single crystal was also investigated with the mass spectrometer. The activation heats and entropies measured for the trimer, tetramer, and pentamer at average temperatures of $512^{\circ} \mathrm{K}, 508^{\circ} \mathrm{K}$, and $548^{\circ} \mathrm{K}$ respectively were as follows: $\mathrm{Cu}_{3} \mathrm{Cl}_{3}\left(\Delta \mathrm{H}^{*}=33.0(0.4) \mathrm{kcal} / \mathrm{mole}, \Delta \mathrm{S}^{*}=28.2(0.7)\right.$ eu. $) ; \mathrm{Cu}_{4} \mathrm{Cl}_{4}\left(\Delta \mathrm{H}^{*}=35.6(0.5)\right.$ $\mathrm{kcal} / \mathrm{mole}, \Delta \mathrm{S}^{*}=31.7(1.0) \mathrm{kcal} / \mathrm{mole}$; and $\mathrm{Cu}_{5} \mathrm{Cl}_{5}\left(\Delta \mathrm{H}^{*}=42.6(1.5) \mathrm{kcal} / \mathrm{mole}\right.$, $\Delta S^{*}=32(3)$ eu.).

Each of the three vapor species displays an entropy barrier, but no enthalpy barrier to sublimation. The vaporization coefficients for each of the vapor species are temperature independent and have the following values: $\ddot{\alpha}_{v}\left(\mathrm{Cu}_{3} \mathrm{Cl}_{3}\right)=0.33(0.02) ; \alpha_{v}\left(\mathrm{Cu}_{4} \mathrm{Cl}_{4}\right)=0.31(0.2) ;$ and $\alpha_{v}\left(\mathrm{Cu}_{5} \mathrm{Cl}_{5}\right)=0.22(0.03)$. The mechanism proposed for the sublimation of each vapor species from the (11l) face of a $\mathrm{CuCl}$ single crystal involves a rate limiting step of reorientation of the molecular species between a kink position and the adsorbed state on the crystal surface. A theoretical interpretation of the sublimation of the trimer was performed from the partition functions for the gaseous species and a proposed activated complex. The activated complex proposed for the trimer involved a species having the stmacture of the trimer gas molecule rotating in one dimension and undergoing torsion oscillations in two dimensions. 
COO-1140-205

1972 , October 31

Page 12

\section{SPACE AND FACILITIES}

The building which houses the Space Technology Center, constructed in part with funds from NASA, was dedicated in September. High temperature research has been assigned a ground floor laboratory and three offices. Adequate power has not ret been provided to the laboratory, so that experiments cannot yet be done. Some equipment has been moved over, but the major move has not been accomplished.

The small computer for dedicated use with the quadrupole mass spectrometer has been ordered, and delivery of it and ancillary equipment is expected near the end of November. The continuing emphasis on the application of small computers for laboratory purposes is being placed on two aspects. The first is to allow the scientist $\because 0$ be closer to and to be more a party to the experiment than previously. He sees results usually on an oscilloscope in so-called real-time, i.e. while the experiment is in progress, so that he appreciates the progress of the measurements and can conduct the experiment in the most productive and efficient way. Because he is relieved of some of the tending of the apparatus, he can think. The second aspect for emphasis is to permit new experiments which simply could not be performed in the older ways.

For the work in high temperature chemistry we now have six major computer programs for on-line, real-time data acquisition and equipment control. One serves to nieasure, monitor, and record the intensities of signals from the Nuclide Mass Spectrometer as a function of time. The ion intensity can be measured $=$ ither in an analog fashion with the vibrating reed liectrometer or in a digital fashion directly with a pulse-counting chain and a scaler. Analog signals characteristic of the focussing conditions of the mass spectrometer are measured by a digital voltmeter. All data are read into the computer by the program. The second program is an analogous one for operation of the quadrupole mass spectroneter. The third program is one that takes ionization efficiency curves automatically with the Nuclide Mass Spectrometer. The operator specifies the energy range, the energy increments, and the counting interval; and the computer adjusts the electron energy, and records the data. 
COO-1140-205

1972, October 31

Page 13

At the end of any sweep the operator may then ask for another so that signal averaging can be accomplished, or he may then terminate the procedure. The fourth program enables the scientist to obtain shutter profiles in a similarly automatic fashion. The fifth program is one that presents on an oscilloscope screen a plot of the logarithm of the mass spectrometric intensity times the temperature vs. 1/T. The sixth program is one that reads information from the multichannel analyzer into the computer for storage on the disc or magnetic tape. The data may then be retrieved for analysis or display at any subsequent time. Detailed documentation and source program listings are available to those interested.

In order to increase the effectiveness of equipment and to improve the efficiency of the operation of the Nuclide Mass Spectrometer, Mr. Robert I. Sheldon has written a real-time subroutine for automatic focussing. The subroutine was written in Assembly Language, and its purpose is to maximize the intensity of an ion which has been approximately focussed, and to refocus periodically that same ion. The computer reads the intensity of an ion, then puts out a signal to a digital-to-analog converter and associated power supply whose output in turn is applied to the control circuitry of the ion accelerating potential. The program works well and is ready to be incorporated as a subroutine into existing data acquisition and equipment control programs. A flow chart of the program is enclosed as figure 1.

During the past year the X-Y table for the Nuclide Mass Spectrometer has been used to support a four-chamber crucible, and the assembly has been used in a very effective fashion for studies in the titanium-oxygen system. In a single experiment we can now make measurements on more than a single sample in a single environment. The attachment enables the scientist to reduce the time interval between measurements on different samples to a few minutes instead of two days and, more importantly, to reduce the temperature uncertainties arising from different loadings, alignments, and gradients.

\section{LEVEL OF ACTIVITY}

The employment of personnel occurred at substantially the level specified in the revised budget. 
COO- $1140-205$

1972, October 31

Page 14

\section{MISCELLANEOUS}

Several activities at the national level may be mentioned. 1 . Professor Gilles made a site visit for the Research Associate Program of the National Research Council office for Scientific Personnel. 2. He continues to serve on the Review Committee for the Division of Chemical Engineering of Argonne National Laboratory, and will be the new chairman. 3. He serves on an Advisory Committee to the Argonne National Laboratory Center for Educational Affairs. 4. He continues to serve on the Editorial Board of High Temperature Science. 5. He serves on the National Research Council Committee on Computers in Chemistry. 6. He serves on the Editorial Board of Advances in High Temperature.

On the local level: 1. Professor Gilles serves on the Board of Directors of the University of Kansas Center for Research, Inc. 2. He served on a Phi Beta Kappa election committee. 3. He served on the planning committee for the dedication of a new building, the Space Technology Center. 4. His wife still serves on the Board of Education of Unified School District No. 497 encompassirg the Lawrence commundty. and surrounding mural areas. 5. Some measure of publicity arose when the newspaper carried a story picturing tungsten crucibles. 


\section{Lov Soheme to Maxdmive Ion Intengdty}

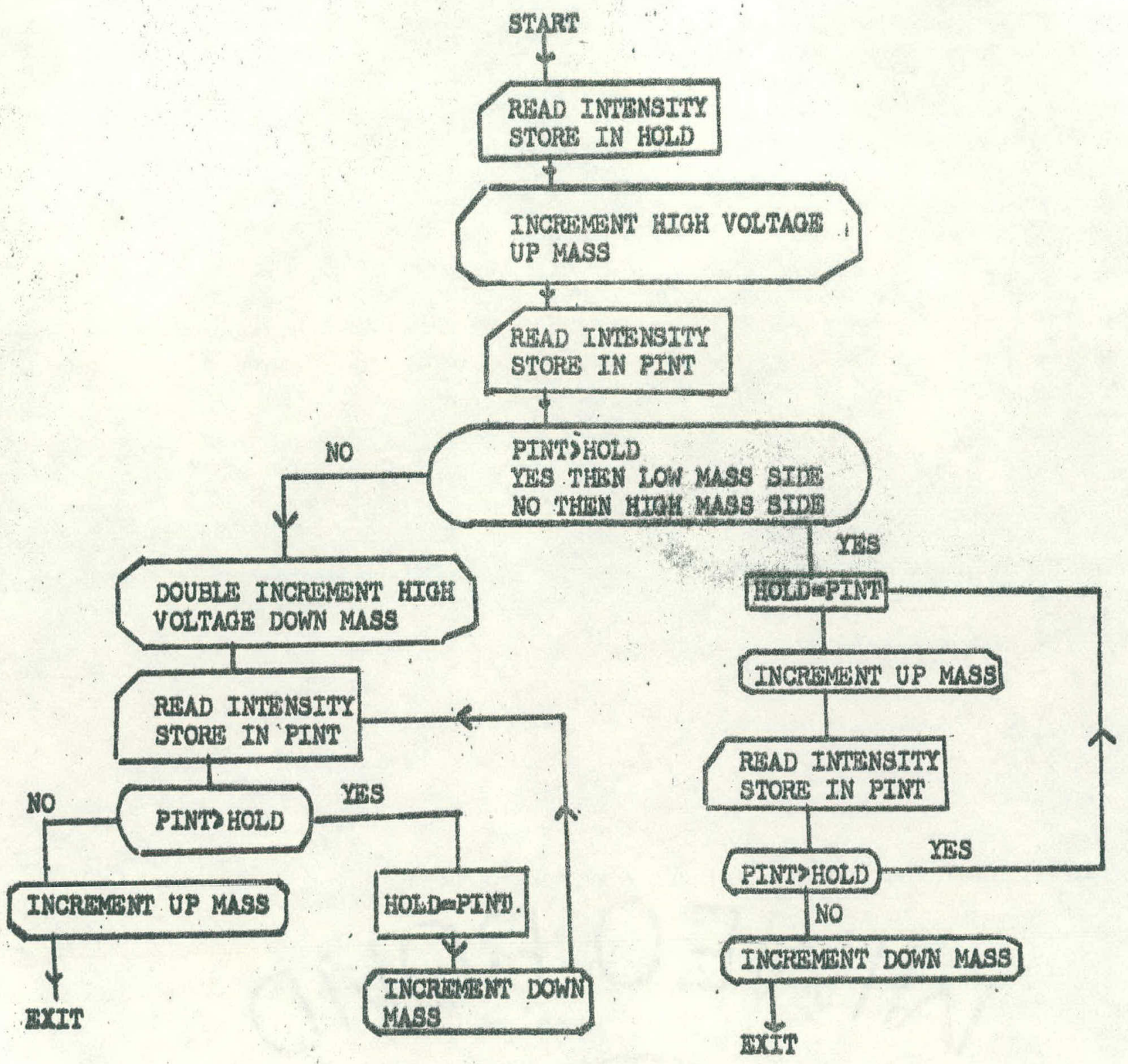


COO-1140-205

1972, October 31

Page 17

TABLE IV

Visitors at the University of Kansas

of Interest to High Temperature Chemists

For the Period 1971, November 1, to 1972, October 31

No. Visitor

V-176 Dr. Hilliam Riggs

E. I. Du Pont de Nemours

Wilmington, Delware

V-177 Dr. Norman Peterson Argonne National Lab. Argonne, Illinois

V-178 Dr. Bruce Conard University of Kansas Lawrence, Kansas

V-179 Dr. Peter Richards Sandia Laboratories Albuquerque, New Mexico

V-180 Prof. Fred E. Stafford Northwestern University Chicago, Illinois

V-I81 Prof. Richard C. Schoonmaker Oberlin College Oberlin, Ohio

V-182 Prof. Lionel M. Raff Oklahoma State University Stillwater, Oklahoma

V-183 Dr. Walter B. Neilsen University of Kansas Lawrence, Kansas

V-184 Prof. Robert C. Bearse University of Kansas Lawrence, Kansas

V-185 Prof. Robert Grimley Purdue University Lafayette, Indiana
Title of Talk

Date Visited

"Electron Emission Spectroscopy" 71, Nov. 4

"Isotope Effects and Diffusion Mechanisms in Solids"

71, Nov. 6

"The High Temperature Vaporization 71, Nov. 11 of $\mathrm{Ti}_{3} \mathrm{O}_{5} \cdot "$

"Light Scattering in Magnetic 71, Nov. 13 Materials"

"Data Acquisition and Equipment 11, Nov. 13 Control Systems"

"The Mechanism of Condensation. 71, Nov. 20 Direct Determination of Coefficients of Condensation of Molecular Beams of $\mathrm{NaCl}$ on Oriented Single Crystals of $\mathrm{NaCl}$."

"The Theoretical Prediction of 71 , Dec. 8 Reaction Mechanism"

"Semiclassical Calculations of Ro- 72 , Jan. I tationally Inelastic Scattering of $\mathrm{HCl}$ and Air"

"Trace Analysis of X-ray Fluor- 72, Feb. 7 escence, Some Biological Applications"

"Use of Angular Distribution 72, Feb. 16 Measurements for Establishing Fragmentation in Mass Spectrometry" 
C00-1140-205

1972, October 31

Page 18

No. Visitor

V-186 Prof. Phillip G. Walbeck IIlinois Inst. of Tech. Chicago, Illinois

V-187 Dr. Thomas C. Teague University of Kansas Lawrence, Kansas

V-188 Dr. Robert G. Behrens University of Kansas Lawrence, Kansas

V-189 Prof. Michael Gross University of Nebraska Lincoln, Nebraska

V-190 Dr. Richard N. Kniseley Institute for Atomic Research Ames Laboratory, Iowa State U. Ames, Iova

V-191 Prof. P. W. M. Jacobs University of Western Ontario London, Ontario, Canada

V-192 Prof. Peter M. Hierl University of Kansas Lawrence, Kansas

V-193 Prof. Peter M. Hierl University of Kansas Lawrence, Kansas

V-194 Prof. Karl E. Spear Pennsylvania State University Crystal Growth" State College, Pennsylvania

V-195 Prof. Ron Wilkins University of Illinois Urbana, Illinois

V-196 Prof. Robert G. Parr Johns Hopkins University Baltimore, Maryland

V-197 Dr. Sin-Shong Lin Army Materials and Mechanics Center Watertown, Massachusetts
Title of Talk

Date Visited

"Failure of Isotropy" 72, Feb. 24

"The Group Contribution Approach, 72, Feb. 28 to Solution Thermodynamics"

"Kinetics of Vaporization of Sub- 72, March 3 stances with Low Vaporization

Coefficients"

"Some Recent Studies of Ion-

72, March 5

Molecule Reactions by Ion

Cyclotron Resonance"

"The Limits of Our Abilities" 72, April 18

"Ionic Defects in Silver Chloride" 72, April 24

"Chemical Reactions and the Collision Complex"

72 , May 1

"Chemical Accelerator Studies of 72 , May 8 Ion-Molecule Reactions"

"High Temperature Chemistry and 72, May 31 
COO-1140-205

1972, October 31

Page 19

TABLE V

Publications Resulting From

High Temperature Chemistry Research

Articles Published

A-79. C00-1140-201. "Professor Leo Brewer: 1971 Palladium Medalist." Paul W. Gilles. J. Electrochem. Soc., 119 [1] 5C-7C (1972), January.

A-80. C00-1140-202. "High Molecular Weight Boron Sulfides. VIII. Vapor Pressures of $\mathrm{B}_{2} \mathrm{~S}_{3}(\mathrm{~g})$ and $\mathrm{B}_{4} \mathrm{~S}_{6}(\mathrm{~g})$ over Stoichiometric $\mathrm{B}_{2} \mathrm{~S}_{3} . "$ Horng-yih Chen and Paul W. Gilles. J. Phys. Chem., 76 [14] 2035-2038 (1972), July 16

\section{Articles Submitted for Publication}

C00-1140-204. "Rare Earth Sulfides at High Temperature. I. On the Existence of Equilibrium in Knudsen Cells." Richard L. C. Wu and Paul W. Gilles. J. Chem. Phys.

\section{TABLE VI}

Talks and Papers at Meetings

T-158 Department of Chemistry, Colorado State University, Ft. Collins, Colorado. Invited talk -- "High Temperature Vaporization and Thermodynamics of Refractory Materials." 1971, November 17.

T-159 Department of Chemistry, St. Olaf College, Northfield, Minnesota. Invited talk -- "High Temperature Vaporization and Thermodynamics of Refractory Materials." 1971, November 19.

T-160 Department of Chemistry, Carleton College, Northfield, Minnesota. Invited talk -- "Automatic Data Acquisition and Control of Equipment with Digita? Computers." 1971, November 19.

T-161 Department of Chemistry, State University of New York at Stony Brook, Stony Brook, New York. Invited talk -- "High Temperature Vaporization and Thermodynamics of Refractory Substances." 1972, February 4.

T-162 Department of Chemistry, University of Nebraska, Lincoln, Nebraska, Invited talk -- "High Temperature Vaporization and Thermodynamics of Refractory Substances." 1972, March 3.

T-163 Discussion Club, University of Kansas, Lawrence, Kansas. "University of Kansas Chemical Physics Trilevel Computer Network." 1972, March 13. 
C00-1140-205

1972, October 31

Page 20

\section{TABLE VI (continued)}

T-164 Seventh International Symposium on Reactivity of Solids, School of Chemistry, University of Bristol, Bristol, England. "Electron Microscopy Studies of the Surface Structure of $\mathrm{KCl}$ Crystals Vaporized Under Near-Equilibrium Conditions." 1972, July 21.

T-165 Gordon Research Conference, Proctor Academy, Andover, New Hampshire.

"Calculation of Composition Range and Congruently Vaporizing Composition for $\mathrm{Ti}_{3} \mathrm{O}_{5}$ at $1900^{\circ} \mathrm{K}$ Using Mass Spectrometric Data Collected Under Computer Control." Bruce R. Conard and Paul V. Gilles. 1972, August 8.

T-166 Gordon Research Conference, Proctor Academy, Andover, New Hampshire.

"Vaporization Kineties of Cuprous Chloride." Dean E. Peterson and Paul W. Gilles. 1972, August 9.

T-167 Gordon Research Conference, Proctor Academy, Andover, New Hampshire.

"Discrepancies in the Dissociation Energies of Some Rare Earth Monosulfides." Robert G. Behrens and Paul W. Gilles. 1972, August 10. 